\title{
Domingo Figarola-Caneda, bibliógrafo, biógrafo, compilador y editor de la Condesa de Merlín y Gertrudis Gómez de Avellaneda
}

\author{
Domingo Figarola-Caneda, bibliographer, biographer, compiler and editor \\ of the Countess of Merlín and Gertrudis Gómez de Avellaneda
}

\author{
Beatriz Ferrús Antón
}

Universitat Autònoma de Barcelona. beatriz.ferrus@uab.es

Recibido: 09/05/2017. Aceptado: 04/09/2017

Resumen: Domingo Figarola-Caneda (Cuba 1852-1926) fue periodista, bibliógrafo, humanista, y el primer director de la Biblioteca Nacional de Cuba. Entre sus biografías, bibliografías y textos ensayísticos de diferente signo se encuentran dos estudios de referencia de la Condesa de Merlín y de Gertrudis Gómez de Avellaneda. Estos trabajos no sólo suponen la recuperación de textos de dos personalidades literarias femeninas de suma importancia para la isla de Cuba, en un momento en el que las escritoras del XIX apenas habían recibido atención crítica, sino también la revalorización de sus escritos personales en fechas muy tempranas. Este artículo aborda la especificidad del trabajo de Figarola-Caneda en estas obras, al tiempo que analiza el valor ideológico de su propuesta.

Palabras clave: Domingo Figarola-Caneda; Condesa de Merlín; Gómez de Avellaneda; literatura de mujeres.

\footnotetext{
Abstract: Domingo Figarola-Caneda (Cuba 1852-1926) was a journalist, bibliographer, humanist, and the first director of Cuba's National Library. Amongst his biographies, bibliographies, and essays of different nature, there is reference material on the Condesa de Merlín and Gertrudis Gómez de Avellaneda. This material implies not only the recovery of texts written by two female literary personalities of the utmost importance for the island of Cuba -at a time when women writers of the $19^{\text {th }}$ century hardly received any critical attention-, but also the appreciation of their personal writings in very early dates. This article discusses the specificity of Figarola-Caneda's work regarding these texts, analyzing at the same time the ideological value of his proposal.

Keywords: Domingo Figarola-Caneda; Condesa de Merlín; Gómez de Avellaneda; Women's literature.

॥ Ferrús Antón, Beatriz. 2017. "Domingo Figarola-Caneda, bibliógrafo, biógrafo, compilador y editor de la Condesa de Merlín y Gertrudis Gómez de Avellaneda". Quaderns de Filologia: Estudis Literaris 22: 155-171. doi: 10.7203/ qfed.22.11257
} 

Las figuras de la Condesa de la Merlín (1789-1852) y de Gertrudis Gómez de Avellaneda (1814-1873) son, de distinto modo, enormemente significativas para la historia de la literatura de mujeres, en tanto pioneras dentro del proceso de emergencia de la escritora profesional; pero también para la historia de la literatura cubana y transatlántica, dada la posición intersticial que ocupan (Ródenas, 1998; Ezama, 2009b): "La Condesa de Merlín pertenece a esa pléyade de cubanos que, esparcidos fuera de su patria, se distinguieron, brillaron, a pesar de lo cual, en Cuba se les conoce poco, mal o tan solo de nombre" (Figarola-Caneda \& Boxhorn, 1928: XX)

Asimismo, en torno a la personalidad de ambas se construye una "mitología de autor", que ha fomentado diferentes reapropiaciones desde los estudios de género, poscoloniales, la literatura de viajes, los análisis de identidades literarias nacionales etc., mientras ha contribuido, en ocasiones, a una lectura parcial de su obra; al tiempo que a la edición reiterada de algunos de sus textos y al mayor olvido de otros, especialmente en el caso de Gómez de Avellaneda (Ezama, 2009a) ${ }^{1}$.

Desde aquí, quienes nos hemos aproximado al estudio de estas autoras nos hemos encontrado con los significativos e ineludibles trabajos, todavía a día de hoy, de Domingo Figarola-Caneda (1852-1926) compilador, bibliógrafo, biógrafo y editor de La condesa de Merlín. María de la Merced Santa Cruz y Montalvo. Estudio bibliográfico e iconográfico, escrito en presencia de documentos inéditos y de todas las ediciones de su obra. Su correspondencia íntima (1789-1832), París: Editions Excelsior, 1928, y de Correspondencia intima, Madrid-París: Industrial Gráfica Reyes, 1928, extraída del libro anterior, con traducción del francés de Boris Bureba ${ }^{2}$ y prólogo de Emilia Boxhorn, viuda del autor, que publicaría póstumamente su investigación sobre ambas figuras.

Por ello, apenas un año después, encontramos Gertrudis Gómez de Avellaneda. Biografía, bibliografía e iconografia, incluyendo muchas cartas, inéditas o publicadas, escritas por la gran poetisa o dirigidas a ella, y sus memorias, Madrid: Sociedad General Española de Libre-

\footnotetext{
${ }^{1}$ Véase el larguísimo listado de ediciones de la "Autobiografía" que recoge en la bibliografía de su trabajo Ezama (2009a), frente a la literatura de viajes todavía por recuperar de la que la estudiosa habla en su artículo.

${ }^{2}$ Isidoro Bureba Muro (1892-1972) fue un reconocido periodista, editor y traductor al francés. Su editorial sería durante la posguerra un referente de la literatura infantil y juvenil.
} 
ría, 1929, que había sido precedida por la edición de unas Memorias inéditas de la Avellaneda, anotadas, en 1914 para Imprenta el Siglo XX en la Habana. Estos textos constituyen un buen ejemplo de los usos de la bibliografía y de la historia de la edición en español en el siglo XIX, pues se habían gestado durante las tres décadas anteriores, de sus problemáticas generales, así como específicas del contexto latinoamericano y, muy particularmente, de la literatura de mujeres. De esta forma, el objetivo de este trabajo es estudiar en detalle los fenómenos aquí enunciados y el papel que los trabajos de Domingo Figarola-Caneda han jugado en la tradición de lectura de estas autoras.

\section{Domingo Figarola-Caneda y la edición de textos en/de el siglo XIX}

El artículo de Rivera y Crespo (2012) "Domingo Figarola-Caneda, el primer director de la Biblioteca Nacional de Cuba" dibuja el retrato de un gran amante de las letras cubanas y del mundo del libro, como periodista, historiador, promotor de tertulias literarias, así como bibliógrafo y bibliófilo, "un celoso guardián de la belleza del ejemplar, de su calidad de edición e impresión" (Rivera y Crespo, 2012: 22). Para las autoras, éste contribuyó desde su obra a la consolidación de una identidad cultural patria independiente. De ahí la importancia que Gertrudis Gómez de Avellaneda y la Condesa de Merlín, así como otras figuras cubanas, tendrían en sus estudios:

Domingo Figarola-Caneda dedicó una gran parte de sus actividades a reunir datos acerca de tres personajes cubanos, por los que sintió admiración o devoción: la condesa de Merlín, Gertrudis Gómez de Avellaneda y José María Heredia. Muchos años de paciente labor convirtieron su casa en un archivo imponente en que los libros, revistas, diarios, anotaciones, formaron montones de legajos que constituían su orgullo (Figarola-Caneda \& Boxhorn, 1929: 7).

No es el objetivo de este ensayo indagar en el perfil del letrado, sino servirnos de éste cómo contexto para comprender el trabajo realizado en las obras objeto de análisis. Si el artículo de Kordic (2006) hablaba de la especificidad de la metodología ecdótica aplicada a textos coloniales hispanoamericanos, el libro de Alejandro Higashi (2013), Perfiles para una ecdótica nacional. Crítica textual de obras mexicanas de los siglos 
$X I X y X X$, no solo constituye una importante reflexión sobre la tradición editorial mexicana desde el siglo XIX al presente, sino por extensión latinoamericana y del mundo del libro en español, marcando una clara diferencia entre la crítica textual, aplicada a textos de la herencia clásica, frente a la que se ocupa del legado decimonónico. Higashi dibuja un contexto mediatizado por la urgencia de la publicación en prensa, abundante, efímera, dispersa... y por la consolidación de la figura del escritor profesional, que necesita "escribir para vivir"; al tiempo que por la falta de editores conscientes de la importancia de la crítica textual, por la carencia de un trabajo reflexivo que cuidara el texto más allá de su circulación adscrita a la urgencia comercial.

Para el investigador mexicano la edición de textos en/de el siglo XIX adquiere especificidad ecdótica y es todavía un campo en construcción (véase para el caso español, Penas, 2013). Por eso, si el legado de Figarola-Caneda es signo de su tiempo, también se singulariza dentro del mismo y se sirve de lo que Higashi llama "bibliografía analítica como disciplina auxiliar para la crítica textual" (2013: 182), a la vez que de la "intuición” genética, historiográfica y, en general, editorial, de quien veía el mundo del autor y del libro como objeto patrimonial, más que mercantil, de quien era capaz de anticipar la importancia de la literatura de mujeres en unos años en que ésta era totalmente secundaria.

No debe olvidarse que, como describe Fernández Sánchez, la bibliografía estuvo ligada desde sus orígenes más remotos a la biografía ${ }^{3}$, aunque en la segunda mitad del siglo XIX: "Estos autores atribuyen a la bibliografía una misión única: el suministro de materiales con los que escribir la historia literaria, entendida como narración y no como interpretación" (1994: 270).

Por eso los libros de Figarola-Caneda continúan siendo, casi cien años después, de enorme actualidad y rigor. Los dos presentan una misma estructura: un ingente trabajo documental precede a la edición anotada de un epistolario o de unas memorias, que se supieron lo suficientemente destacables para recibir, en el caso de la condesa de Merlín, la traducción y edición aislada de la Correspondencia íntima y, en el de Gómez de Avellaneda, la publicación exenta de las Memorias inéditas,

\footnotetext{
${ }^{3}$ Fernández Sánchez (1994) explica cómo los orígenes de la bibliografía están ligados a los listados de obras que acompañaban a hagiografías y biografías de figuras singulares de la antigüedad.
} 
como se ha detallado. Veamos, a continuación, la importancia que tienen para la lectura crítica y la historia editorial de ambas autoras.

\subsection{La Condesa de Merlín}

Este libro parte de la constatación de una carencia. Domingo FigarolaCaneda reconoce la importancia del personaje y se asombra ante la pérdida de su patrimonio textual ${ }^{4}$ :

¡Cuánto documento y de diverso género desaparecido! ¡De cuántas mujeres, sin los méritos de la Merlín, hemos leído biografías y estudios críticos abundantes en detalles y lujosamente publicados bajo la firma de escritores de fama y por los primeros editores de París! ¡Y de ella no hay publicada ni una biografía que puede ni debe leerse! (FigarolaCaneda \& Boxhorn, 1928: XVII).

Así durante casi quinientas páginas se ocupa de subsanar esta falta, reuniendo los materiales recopilados a lo largo de casi tres décadas para trazar, en primer lugar, una exhaustiva biografía, ajena a los errores y los vacíos de otros intentos. De este modo, ésta, de notable extensión, se divide en once puntos, todos ellos apoyados por documentos: la familia, fecha de nacimiento, primeros pasos de la condesa, el convento de Santa Clara, su llegada a España, el general O'Farill, José I Rey de las Españas, el general Merlín, datos sobre la boda de la condesa, huida de España, en París, viajes, su obra literaria y su muerte. María de las Mercedes Santa Cruz y Montalvo aparece aquí dibujada como una mujer de importante abolengo, a uno y otro lado del océano, que acaba siendo azarosa protagonista de un momento de suma trascendencia en la historia de España, además de como una intelectual, especialmente dotada para la literatura y la música, cuyos escritos literarios sirven de intertexto a la vida contada.

En segundo lugar, se incluye una "bibliografía", que se ramifica en múltiples e interesantes direcciones, pues no sólo se estudian en detalle aquellos "restos" que quedan de la biblioteca perdida de la autora, también de su archivo personal. De la misma manera, se nos presentan

\footnotetext{
${ }^{4}$ No podemos olvidar, como recuerda Caballero (2006), que pese a la falta que se constata, Francia fue más avanzada que España en el XIX en lo que a conservación documental, en general, y de literatura de mujeres, en particular, se refiere.
} 
textos de prensa que anuncian la publicación de sus obras o las comentan; además se recoge el epistolario con Domingo del Monte, anotado como Cartas inéditas del Centón epistolario (1844-1845)5.

Entre los manuscritos del marqués de Montelo, adquiridos por la Biblioteca Nacional en 1907, se halla uno por el cual hemos conocido la colaboración que prestó Montelo a la obra La Havane de la condesa de Merlín.

En el Centón Epistolario, y también en la Revista de la Biblioteca Nacional, se hallarán cartas de Saco, Del Monte y Montelo que dan noticias de la participación de ellos en La Havane (Figarola-Caneda \& Boxhorn, 1928: 115)

Aquí vemos cómo Del Monte es el centro de una correspondencia donde son varios los amigos cubanos que han visitado a la escritora, quien necesita conversar sobre la isla y refrescar datos. Otras veces, es ella misma la que anuncia, en sus misivas, su proyecto o propone encuentros para concretarlo. Éstas se convierten en testimonio del proceso "genético" de La Habana y así sabe destacarlo el bibliógrafo cubano:

Para un editor "genético", la edición "definitiva" es una etapa en la historia del texto, sin duda privilegiada, pero que no debe considerarse como la última. Abre la vía a la revalorización de las versiones anteriores y esbozos preparativos, se da lugar importante a las cuestiones de la génesis de la obra y se pone el acento en el "movimiento" de la escritura (Orduna, 2000: 89).

Además, se introduce una "bibliografía analítica"6 de la autora. Todo ello no solo nos da a conocer, desde una mirada poliédrica, a ese perso-

\footnotetext{
${ }^{5}$ Ésta es la referencia dada en la propia obra sobre los textos inéditos. El Centón Epistolario de Domingo del Monte, sería publicado más tarde, con prólogo y notas de Domingo Figarola-Caneda, en La Habana: Imprenta del Siglo XX, en 7 volúmenes. Solo de los tres primeros se haría cargo el bibliógrafo, pues su publicación abarcaría de 1923 a 1957. Resulta de sumo interés el prefacio al primer volumen, firmado por FigarolaCaneda, pues en él se insiste en la importancia de la edición las correspondencias personales para la historia, literaria y no solo, pero también, de la bibliografía como ciencia fundamental para ambas. La correspondencia de 1844-1845 se encuentra en el tomo VI, a cargo de Manuel I. Mesa y Rodríguez, impreso en 1953.

${ }^{6}$ El trabajo recoge textos sobre y de la condesa, acompañados de citas de notas en prensa y comentarios descriptivos sobre los mismos y su historia editorial.
} 
naje hurtado a los lectores, sino que sirve de preparación para la edición del penúltimo de los apartados "Correspondencia":

La importancia que tiene el estudio y la publicación de las cartas en toda obra histórica, es un hecho que no admite la más leve discusión, y por lo mismo, de ahí se deriva todo el interés que en la obra de la Condesa de Merlín han de ofrecer todas las cartas (inéditas) -menos una- que hoy hacemos figurar.

Pero no podrá nunca la generalidad de los lectores formarse una idea exacta de la suma incalculable de trabajo que hemos tenido que emplear hasta llegar a coleccionar el número de ellas que ofrecemos, y más todavía, a estudiarlas e interpretarlas a fin de explicarlas y relacionarlas como ellas exigen para el complemento de nuestra obra... para salvar del olvido y de la destrucción este conjunto de documentos que representa para la Francia y para Cuba, un precioso caudal de sentimientos, de impresiones, de rasgos geniales, de noticias, de datos, del alma, en fin, de una de las mujeres más ilustres del XIX (Figarola-Caneda \& Boxhorn, 1928: 181-182).

Como el editor indica se trata de material inédito, autógrafo, carente de fechas que deben ser dilucidadas y ordenadas, trabajo que no hubiera podido hacerse sin la indagación archivística previa. Las epístolas quedan divididas en tres apartados: De la condesa de Merlín a Philarète Chasles, el más extenso y significativo, de la misma a varios y un apéndice de cartas relacionadas con ésta. El principal corresponsal es presentado como un "seductor", que carece de méritos:

Tanto seduce, que llega a mostrarlo, a creerlo firmemente, a quererlo hacerlo creer, lo cual es peor... A su celebridad contribuyeron mucho los acreedores a los que pagaba tarde, mal o nunca... y también un poco -¡oh! muy poco porque es indiscutible su talento- la condesa de Merlín. (Figarola-Caneda \& Boxhorn, 1928: 186).

El libro concluye con una iconografía, que no solo reúne los más importantes retratos de Santa Cruz y Montalvo o de sus familiares inmediatos, sino notas y comentarios en periódicos o en textos de circulación privada referidos a ellos.

Por tanto, nos encontramos ante un libro híbrido que hace un uso muy personal de la ciencia bibliográfica, la amplía, la mezcla, para aca- 
bar por presentar la edición anotada ${ }^{7}$ de un epistolario, como un hito de suma importancia, que permite conocer los últimos años de Santa Cruz y Montalvo, y "asomarnos" a la génesis de su trabajo, completando la cadena de sus escritos autobiográficos, como sucedía con la correspondencia a Del Monte:

[...] Leer la correspondencia con su amante es reproducir toda una historia que cincela el taller de Merlín...Se presupone colaboración, pero el tono y las recomendaciones femeninas permiten inferir quién lleva las riendas; ella es la autora y él un cualificado e íntimo manager literario en el que se confía hasta el punto de entregarles los borradores, es decir, los únicos “originales” (Caballero, 2006: 22).

Si las cartas se editan en francés, lengua que Domingo FigarolaCaneda demuestra conocer a la perfección, la importancia de la Correspondencia íntima se reconoce al instante, lo que llevó a que Emilia de Boxhorn la publicara desgajada de la obra anterior y traducida al español en el mismo año, siguiendo un proceso semejante, aunque inverso, al que vivirían las Memorias inéditas:

La publicación en español de esta correspondencia de la Condesa de Merlín, no obedece a ningún fin bastardo. Domingo Figarola-Caneda quiso darlas a la luz, primero en el idioma en que fueron escritas. Sabiendo que habían fatalmente de causar cierta perturbación en los juicios que todos formaron sobre la insigne criolla, era lógico que deseara reflejar fielmente los autógrafos... Pero también en su deseo de dar mejor a conocer tan discutido personaje de aquella época tan agitada, concibió la idea de publicar su correspondencia en la lengua de su autora... Así pues, al traducir las cartas de la Condesa, no hacemos sino prescindir de la forma en que fueron escritas y reflejar fielmente el pensamiento que las dictó. Casi nos atreveríamos a decir que fue la misma autora la que tradujo dicho pensamiento y que nosotros nos limitamos a restablecer el orden natural de las cosas (Boxhorn, 1928b: V-VI).

El prólogo a la traducción española vuelve a retratar a un erudito consciente de la importancia del autógrafo, al tiempo que refleja el trabajo cuidadoso de Emilia Boxhorn, que no duda en recurrir a un reco-

\footnotetext{
${ }^{7}$ Las notas que acompañan al texto son escasas y breves, aportan referencias sobre fechas, lugares o textos propios citados por la autora.
} 
nocido traductor y en reflexionar sobre la condición "bilingüe" de quien escribió estas cartas. Si la breve biografía de la condesa que precede a esta traducción habla del influjo del "fuego de la sangre criolla" en su escritura, coincidimos con Caballero (2006) en que estas páginas retratan a una escritora, que da instrucciones a su secretario:

ya me lo pagarás más tarde o lo que más valdría, terminando de arreglar mi manuscrito enseguida... Además, envíame seguidamente, en un paquetito, por la diligencia, el manuscrito inglés, que debe de estar terminado... (Merlín, 1928b: 45).

Esta carta os será entregada desde mi casa. Adjunto la que va dirigida a M. Havas. La uniréis al extracto o a la revista que lo contiene, así como a los párrafos señalados, haréis llevar todo bajo sobre a mi casa (Merlín, 1928b: 55).

Del mismo modo que dibujan a una profesional consciente del valor de su producción, de la necesidad de rescribir un texto antes de hacerlo llegar a los lectores:

Si lees algunos fragmentos de nuestra obra a Cassagnac, creo que harías bien eligiendo una carta de costumbres y otra más severa... Hay que suavizar algo las cartas de los Estados Unidos y acerca del gobierno de La Habana...Piensa, sobre todo, en lo preciosas que son las copias, o, mejor dicho, los borradores que tú tienes, puesto que no he guardado de ellos ninguna copia (Merlín,1928 b:114-116)

Domingo Figarola-Caneda y Emilia de Boxhorn no solo nos legan un trabajo de gran peso documental, sino que atentos al valor de los autógrafos los recuperan para la historia editorial de la condesa de Merlín, siempre convencidos de hallarse ante una figura pionera y singular, que propicia la reapropiación fantasiosa. Por eso, retratarla en el proceso de gestión de su obra constituye un acto de reivindicación.

\subsection{Gertrudis Gómez de Avellaneda}

Como habíamos anticipado, es, de nuevo, la viuda de Figarola-Caneda quien da a la luz el libro que había sido precedido por la publicación de la edición de Memorias inéditas con motivo del centenario del nacimiento de la autora. El impulso es el mismo que había guiado el texto 
sobre la condesa y su estructura es semejante. No obstante, ahora la biografía es el resultado de unas notas que ya habían sido publicadas: "Extraeremos principalmente estas notas de un estudio publicado en la Revista de Cuba (Diciembre de 1877), bajo el título "Poetisas cubanas. Gertrudis Gómez de Avellaneda" (Figarola-Caneda \& Boxhorn, 1929: 119), posiblemente porque el bibliógrafo no había visto la necesidad de escribir un trabajo exhaustivo, ya porque Avellaneda era muy conocida o porque su fallecimiento le impidió concluirlo. Sea como fuere, la biografía, que incide en la precocidad de su vocación de lectura y escritura, deriva, ante todo, en un relato de sus hitos literarios y de su singularidad en el mundo de las letras, pero donde se dice: "De sus virtudes domésticas nos ha dejado el señor Pastor Díaz un elogio notable, que la recomienda a la estimación de la posteridad como dechado de esposas" (Figarola-Caneda \& Boxhorn, 1929: 15), cita que habla todavía de una mirada muy ideologizada hacia la figura de la mujer de letras, que fue muy frecuente entre los cronistas y críticos de Gómez de Avellaneda y de otras escritoras del XIX.

Sin embargo, Figarola-Caneda supera estas inercias y dibuja una imagen de gran talento, que ha sido capaz de publicar sus obras completas, un logro singular en una autora del periodo, mientras denuncia el imperdonable olvido en el que muere y los escasos homenajes con que se acompaña su deceso. Es decir, el destino compartido de Mercedes de Santa Cruz y de Gertrudis Gómez de Avellaneda ha sido el olvido, por mujeres, por escritoras, pero también por su identidad intersticial, entre países y literaturas. Entre los documentos que el libro adjunta están la reclamación de los restos de la literata por las instituciones cubanas y las últimas voluntades que ésta registra en su país, ambos en sintonía con el trabajo de recuperación y reapropiación que este libro pretende.

La bibliografía representa un desafío, pues la obra es tan ingente, sobre todo en prensa, que se revela como inalcanzable, las dedicatorias de los textos, los sueltos de prensa, documentos personales, datos de los estrenos y notas críticas que los comentan, permiten comprender el contexto de edición, producción y difusión de sus escritos. Se subrayan especialmente las dedicatorias a Cuba y la presencia y las menciones de Gómez de Avellaneda en compilaciones sobre poetas cubanos y en diferentes libros dedicados a la isla.

Asimismo, son varias las referencias a publicaciones, antologías y homenajes con presencia de escritoras, lo que testimonia el compromi- 
so de esta con sus congéneres (Ezama, 2016). La iconografía es tanta -litografías, retratos, medallas conmemorativas etc.- que simboliza su extraordinaria singularidad.

Además, la ingente correspondencia de o $a$ la autora, que se edita, dibuja un mapa de relaciones con políticos y literatos de la época que nos descubre un enorme trabajo de gestión y promoción de publicaciones: "Tendré el mayor gusto en ayudar a usted, en lo que mis flacas fuerzas me lo permitan, a la redacción del periódico literario que se va a publicar bajo su dirección" (Condesa de Merlín, 31 de Octubre de 1845: 156). Alarcón, Concepción Arenal, Breton de los Herreros, Fernán Caballero, la Emperatriz Eugenia, Hartzenbusch, Alberto Lista, Francisco Martínez de la Rosa, el Duque de Rivas, Ramón de la Sagra, Zorrilla etc., son algunos de los corresponsales.

Las cartas han sido, en ocasiones, donadas por los receptores de las mismas, que saben del proyecto del bibliógrafo. En ellas la escritora comenta cómo la edición, distribución y estreno de sus textos escapa, muchas veces, de su mano, escribe cartas-prólogo a la prensa que preceden a la publicación de alguno de sus trabajos o envía a los periódicos diferentes notas con motivo de la muerte de su marido.

Pero dos temas recorren la mayor parte de documentos compilados: el primero será el enorme malestar que Gertrudis Gómez de Avellaneda experimenta al no haber sido admitida en la Real Academia. Se recogen las epístolas a través de las cuales trata de lograr su ingreso y, después, la opinión de Emilia Pardo Bazán quien, ante la misma circunstancia, dirá: "tengo conciencia de mi derecho a no ser excluida de una distinción literaria como mujer" (1929: 170); pero sabe del peligro de mostrarse crítica con los periódicos, por lo que opta por mantenerse en un discreto lugar.

El segundo tiene que ver con la posición fronteriza de su inscripción autorial: "se me excluía del número de los escritores cubanos por no ser yo cubana, sino madrileña; cosa que, a entenderse como suena, me parecería dicha ex profeso para hacerme reír" (Figarola-Caneda \& Boxhorn, 1929: 240). Por ello agradece especialmente la dedicatoria del Álbum poético-fotográfico de las escritoras cubanas, que no sólo no duda de su adscripción patria, sino que la recuerdan como fundadora de un linaje de escritoras liderado por Domitila García Coronado: "Yo no dudo un solo instante que estos sencillos y tiernos cantos algo tendrán para vos de tristes y de gratos, pues en ellos oiréis la voz de la 
patria que desde lejos envía a su hija adorada un suspiro, que llegará hasta vos en alas de las puras y frescas brisas tropicales" (1868, de la dedicatoria, $\mathrm{sp}$ ).

No obstante, es la edición de esas Memorias inéditas con las que concluye el gesto que más nos interesa: "Estas memorias anotadas por mi fueron publicadas en 1914 (Habana, Imprenta el Siglo XX). La tirada, muy limitada, se halla completamente agotada, por lo que me parece reproducirlas en este volumen" (Figarola-Caneda \& Boxhorn, 1929: 249), puesto que leídas en el conjunto del material organizado en el libro no sólo alcanzan mayor resonancia y significado, sino que constituyen, como en el caso de la Correspondencia íntima, un eslabón de gran interés en el conjunto de los escritos autobiográficos de Gómez de Avellaneda (Ezama, 2009a y 2011).

\section{Literatura de mujeres y "mitologías" de autor: una lectura sesgada}

Gertrudis Gómez de Avellaneda escribió una biografía de María de las Mercedes de Santa Cruz con la que se acompañó la edición española de La Habana (Madrid, 1844), ésta contribuye a delinear la identidad intersticial de la que hablábamos en páginas precedentes:

En medio de las varias causas que se reúnen para impedir que los hijos de Cuba, dotados en general de una viva y vibrante imaginación, hayan podido aclimatar, por decirlo así, la literatura en su suelo, pueden vanagloriarse de presentar a Europa un nombre ilustre, que brilla ventajosamente colocado entre los más distinguidos de los escritores contemporáneos. Las obras de la señora condesa de Merlín, si bien las vemos con disgusto destinadas a enriquecer la literatura francesa, son timbres honoríficos para el país que la vio nacer (Gómez de Avellaneda, 1844: V).

Con la que se siente solidaria: "Todas las impresiones que pinta la autora nos son conocidas, todos aquellos placeres, todos aquellos pesares los hemos experimentado" (Gómez de Avellaneda, 1844: X). No obstante, si para Caballero este prólogo no deja en buen lugar a la condesa (Caballero, 2006: 27), no podemos ignorar que tanto la biografía escrita por Gertrudis Gómez de Avellaneda, como las del propio Figarola-Caneda y Emilia de Boxhorn reflexionan sobre la "mitología de autor" que 
acompaña a las figuras retratadas: mujeres, transgresoras, exóticas en su patria de acogida, etc.

Desde aquí, la investigación que precedió al libro Mujer y literatura de viajes en el siglo XIX, entre España y las Américas (2011) nos llevó no solo a conocer la obra de Domingo Figarola-Caneda, sino a percatarnos de las "inercias de lectura" que habían guiado el acercamiento a las figuras de Mercedes de Santa Cruz y Montalvo y Gertrudis Gómez de Avellaneda; así como de la re-apropiación que de las mismas habían hecho determinadas aproximaciones editoriales y críticas, especialmente desde los años noventa del siglo XX (Ferrús, 2016). Así, nos sorprendía, por ejemplo, la falta de un edición crítica de las Memorias de Gómez de Avellaneda, cuando la Autobiografía o Cartas a Ignacio de Cepeda y la novela $S a b$ habían recibido notable atención. El revelador trabajo de Ángeles Ezama (2009a) "Gertrudis Gómez de Avellaneda: Un siglo de manipulación e invención en torno a su autobiografía (1907-2007)" explicaba algunas de las razones de ese proceso, que podrían ser extrapoladas al caso de la condesa de Merlín:

La puesta en cuestión del modo en que ha sido editada e interpretada la autobiografía de Gertrudis Gómez de Avellaneda se hacía necesaria por varias razones; primero para alcanzar una interpretación más rigurosa de la vida y la obra de la escritora cubana, libre de prejuicios y de idealismos, y más próxima a la verdad de los testimonios conservados. Segundo para dignificar la historia de la autobiografía escrita por mujeres en el siglo XIX (Ezama, 2009a: 18).

Mientras que en su artículo "Los relatos de viaje de Gertrudis Gómez de Avellaneda" (2011) recordaba el "olvido" de algunos de sus textos y la todavía vigente edición de Figarola-Caneda:

La razón de este aparente olvido radica en la difícil localización de dichos relatos, a excepción del ya citado de 1838, que fue editado por Domingo Figarola-Caneda de modo exento en 1914, y luego incluido en una recopilación de documentos sobre Avellaneda hecha por la viuda de Figarola-Caneda, Emilia Boxhorn, en 1929 (Ezama, 2011: 329).

Si en ambos textos Ángeles Ezama incide en la dificultad de recuperación de algunos documentos, también inscribe esta problemática en la que, a nuestro juicio, es una de las razones fundamentales de su relego: 
las particulares condiciones de la historia de la literatura de mujeres, sus silencios y mitificaciones, ampliamente denunciados por el feminismo.

Por otro lado, Caballero Wangüemert editaba en 2011 la Correspondencia íntima de la Condesa de Merlín, pero lo hacía recuperando el trabajo del bibliógrafo cubano: "Mi intervención en el texto se limitó a modernizar, igualar términos [...] Por cierto, las notas no son mías, sino del original francés, con toda seguridad de Figarola-Caneda" (Caballero, 2011: 28).

Sea como fuere, como hemos venido observando, Domingo Figarola-Caneda, con la ayuda indispensable de Emilia de Boxhorn, habría de legar a la historia editorial de María de las Mercedes Santa Cruz y Montalvo y Gertrudis Gómez de Avellaneda dos trabajos que combinan la mejor tradición bibliográfica, historiográfica y editorial de fines del XIX, con un respeto exquisito hacia la literatura de mujeres, consciente de sus "trampas", que se intuyen y se esquivan. Por ello, todavía a día de hoy, sus textos continúan siendo una referencia ineludible en la aproximación a estas autoras, "retratándolas" en el proceso de la escritura, como apuesta política para "otra" historia por venir.

\section{Bibliografía}

Caballero Wangüemert, María. 2006. Estudio preliminar. En Santa Cruz y Montalvo, María de las Mercedes de, (Condesa de Merlín). Viaje a la Habana. ed. María Caballero Wangüemert. Madrid: Verbum.

Caballero Wangüemert, María. 2011. La condesa de Merlín una mujer de frontera. En Santa Cruz y Montalvo, María de las Mercedes de, (Condesa de Merlín). Correspondencia intima. Sevilla: Arcibel.

Ezama Gil, Ángeles. 2009a. Gertrudis Gómez de Avellaneda: Un siglo de manipulación e invención en torno a su autobiografía (1907-2007). Decimonónica 6 (2): 1-23

Ezama Gil, Ángeles. 2009b. Criollas en París. La condesa de Merlín, Gertrudis Gómez de Avellaneda y la duquesa de la Torre. Analecta malacitana 32 (2): 463-482

Ezama Gil, Ángeles. 2011. Los relatos de viaje de Gertrudis Gómez de Avellaneda. Anales 23: 323-351.

Ezama Gil, Ángeles. 2016. La poesía de Gertrudis Gómez de Avellaneda en antologías colectivas (1846-1893). Revista Brasileira do Caribe 33 (17): 203-225.

Fernández Sánchez, José. 1994. Historia de la bibliografía en España. Madrid: Compañía Literaria. 
Ferrús Antón, Beatriz. 2011. Mujer y literatura de Viajes en el siglo XIX, entre España y las Américas. Valencia: PUV-Biblioteca Javier Coy.

Ferrús Antón, Beatriz. 2016. Teatro en otros tiempos de dramáticos hechos. Las mujeres en las leyendas de Gertrudis Gómez de Avellaneda. En Martín, Rebeca \& Parellada, Joaquim (eds.) Una horma para el cuento. Madrid: Iberoamericana.

Figarola-Caneda, Domingo \& Boxhorn, Emilia. 1928. La condesa de Merlín. (María de las Mercedes Santa Cruz y Montalvo). Estudio bibliográfico e iconográfico, escrito en presencia de todas sus obres. Su correspondencia intima (1789-1832). París: Excelsior.

Figarola-Caneda, Domingo \& Boxhorn, Emilia. 1929. Gertrudis Gómez de Avellaneda. Biografía, bibliografia e iconografia, incluyendo muchas cartas, inéditas o publicadas, escritas por la gran poetisa o dirigidas a ella o sus memorias. Madrid: Sociedad Española de Librería.

García Coronado, Domitila. 1868. Álbum poético-fotográfico de las escritoras cubanas. La Habana: Imprenta Militar de la Viuda de E. HS. de Soler.

Gómez de Avellaneda, Gertrudis. 1844. Apuntes biográficos de la señora condesa de Merlín. En Santa Cruz y Montalvo, Mercedes de (Condesa de Merlín). La Habana. Madrid: Imprenta de la Sociedad literaria y tipográfica.

Gómez de Avellaneda, Gertrudis. 1914. Memorias inéditas, ed. Domingo Figarola-Caneda. La Habana: El Siglo XX.

Gómez de Avellaneda, Gertrudis. 2015. Autobiografía y otras páginas, ed. Ángeles Ezama. Madrid: RAE.

Kirkpatrick, Susan. 1991. Las románticas. Madrid: Cátedra.

Kordic Riquelme, Raïssa. 2006. La crítica textual hispanoamericana. Algunas especificaciones metodológicas. Onomazein 13: 191-202.

Méndez Rodenas, Adriana. 1998. Gender and nationalism in colonial Cuba. The travels of Santa Cruz y Montalvo, condesa de Merlín. London: Vanderbilt University Press.

Orduna, Germán. 2000. Ecdótica. Problemática de la edición de textos. Kassel: Reichenberger.

Penas, Ermita. 2013. Sobre la edición de textos de nuestros clásicos realistanaturalistas en el siglo XIX. En Perspectivas críticas para la edición de textos de literatura española. Santiago de Compostela: Universidad de Santiago de Compostela: 191-208.

Rivera, Zoia \& Crespo, Aimée. 2012. Domingo Figarola-Caneda, el primer director de la Biblioteca Nacional de Cuba. Reencuentros 2: 12-30.

Santa Cruz y Montalvo, María de las Mercedes de, (Condesa de Merlín). 1844. La Habana. Madrid: Imprenta de la Sociedad literaria y tipográfica. 
Santa Cruz y Montalvo, María de las Mercedes de, (Condesa de Merlín). 1928. Correspondencia intima, extraída del estudio biográfico, bibliográfico e inconográfico de Domingo Figarola-Caneda. Madrid: Industrial Gráfica.

Santa Cruz y Montalvo, María de las Mercedes de, (Condesa de Merlín). 2006. Viaje a la Habana, ed. María Caballero Wangüemert. Madrid: Verbum.

Simón Palmer, María del Carmen. 2005. Gertrudis Gómez de Avellaneda, agente político. Studi Ispanici 1: 341-348.

Simón Palmer, María del Carmen. 2005. Las finanzas de las escritoras románticas. En A la zaga de tu huella. Homenaje al profesor Cristóbal Cuevas. Málaga: Servicio de Publicaciones Universidad de Málaga: 597-612.

Sommer, Doris (2004). Ficciones y silencios fundacionales. México: FCE. 
